\title{
Interactive effects of light/dark cycle, ECS, physostigmine, and scopolamine on one-way avoidance learning in rats
}

\author{
W. DOUGLAS GAMMON and ROGER K. THOMAS \\ University of Georgia, Athens, Georgia 30602
}

\begin{abstract}
After 6 weeks on a 12-h light-dark cycle, rats were trained during either the light or the dark phase, 4 or $48 \mathrm{~h}$ following ECS or sham ECS, and 30 min following physostigmine, scopolamine, or saline injections. Using "cholinergic excitability" as a hypothetical construct and suggesting that ECS/4 h, physostigmine, and dark-phase training would enhance and that ECS/48 h and scopolamine would reduce cholinergic excitability, it was predicted that the combinations of variables resulting in the highest and lowest excitability values would be associated with the most trials to criterion, that medial values would be associated with the fewest trials, and that intermediate values would be associated with intermediate trials. These predictions were confirmed and supported by a $.79(p<.01)$ correlation between excitability values and trials to criterion. Discussion considered the learning-performance distinction in the present context as well as the possibility that variables other than cholinergic excitability might be involved.
\end{abstract}

Deutsch and his collegues (e.g., Deutsch, 1971; Deutsch, \& Rogers, 1979) have provided much evidence to support a hypothesis, summarized briefly, that too little or too much brain "cholinergic excitability" impairs retention. According to Deutsch and Rogers (1979):

In synapses with normal cholinergic sensitivity, $\mathrm{ACh}$ accumulation may become excessive after anticholinesterase treatment. The postsynaptic membrane may not be able to repolarize and synaptic blockade may ensue.... The anticholinergics, of course, have quite different actions on the synapse. These agent compete with $\mathrm{ACh}$ for cholinergic receptor sites and thereby reduce cholinergic synaptic excitability. (p. 179)

Deutch's hypothesis suggests that there are normal fluctuations in cholinergic excitability following learning, and that the effects of the anticholinesterase or anticholinergic drugs on retention depend upon when they are administered in relation to these normal fluctuations. The combination of normally high, postlearning cholinergic excitability and an anticholinesterase drug is associated with impaired retention. The combination of normally low, postlearning cholinergic excitability and an anticholinergic drug is also associated with impaired retention. Between these too-high and too-low states of cholinergic excit-

Address reprint requests to Roger $\mathrm{K}$. Thomas, Department of Psychology, University of Georgia, Athens, Georgia 30602. W. D. Gammon's present address: Psychology Service, Veterans Administration Hospital, 200 Springs Road, Bedford, Massachusetts 01730 . ability, there is, hypothetically, a range of excitability which is associated with normal retention. Davis (1972) working in the context of Deutsch's hypothesis provided evidence that it applies also to acquisition. In none of these studies has acetylcholine (ACh) been assessed directly; rather, alterations of cholinergic excitability have been inferred on the basis of the known effects of the anticholinesterase (typically, physostigmine) and anticholinergic (typically, scopolamine) agents.

Other variables known to affect brain $\mathrm{ACh}$ include established light-dark cycles and electroconvulsive shock (ECS). Hanin, Massarelli, and Costa (1970) and Saito (1971) have shown that contingent upon an established light-dark cycle, rats show significantly greater release of $\mathrm{ACh}$ during the first few hours of the dark phase. There is direct evidence that brain ACh release is increased following ECS (Richter \& Crossland, 1949) up to $2 \mathrm{~h}$ (Essman, 1972). There is indirect evidence that the release of ACh may be enhanced at least as long as $24 \mathrm{~h}$ post-ECS (Adams, Hoblit, \& Sutker, 1969; Davis, 1972; Davis, Thomas, \& Adams, 1971; Wiener, 1970). Davis (1972) also provided data which suggest that cholinergic excitability may be below normal $48 \mathrm{~h}$ post-ECS. Prewett and Thomas (1976) investigated the effects of both ECS and light-dark cycles on the acquisition of oneway avoidance by rats, and they interpreted their results as being consistent with Davis' (1972) results and Deutsch's hypothesis. Stephens, McGaugh, and Alpern (1967) also examined the combined effects of ECS and light-dark cycle and reported greater amnesia in mice which received the ECS-dark combination; 
this result, too, might be interpreted as being consistent with Deutsch's hypothesis.

The present study examined the interactive effects of ECS, light-dark cycle, and anticholinesterase drug (physostigmine), and an anticholinergic drug (scopolamine). Based on the studies mentioned above, it was expected that training $4 \mathrm{~h}$ post-ECS would be associated with decreased excitability, and that training during the dark phase would be associated with increased excitability. A completely balanced design, involving the aforementioned variables together with appropriate saline injection and sham-ECS groups, was used; a summary of the design may be seen as the first four columns in Table 1 .

Since direct assessments of ACh were not done, it must be emphasized that the phrase "cholinergic excitabililty" as used here has the status of a hypothetical construct. That is, this study is concerned with postulated as opposed to actual cholinergic excitability. The purpose of using "cholinergic excitability" here was to make predictions concerning the interactive effects of the independent variables (see next paragraph) and rats' performances in the acquisition of one-way avoidance.

Specifically, cholinergic excitability was projected as follows: (1) Variables assumed to increase cholinergic excitability at the time of training, namely, $\mathrm{ECS} / 4 \mathrm{~h}$, physostigmine injections, and training dur- ing the dark phase, were each assigned the value, +1 . (2) Variables assumed to decrease cholinergic excitability, namely, ECS/48 $\mathrm{h}$ and scopolamine injections, were assigned the value, -1 . (3) Variables not known to affect cholinergic excitability, namely, sham ECS, saline injections, and training in the light phase, were assigned a value of 0 . Summed treatment weights (shown as column 5 in Table 1) ranged from +3 to -2 . Extrapolating from Deutsch's hypothesis, too much $(+3)$ and too little $(-2)$ cholinergic excitability were predicted to yield the poorest behavioral performances (i.e., the most trials to criterion), medial cholinergic $(0$ and +1$)$ was predicted to yield the best performances, and intermediate cholinergic excitability $(+2$ and -1$)$ was predicted to yield performances intermediate between the poorest and best. These predictions are represented as column 6 in Table 1.

\section{METHODS}

\section{Subjects}

The animals were 144 naive Sprague-Dawley-derived male rats that weighed between 275 and $325 \mathrm{~g}$ and were approximately 90-120 days old at the time of ECS or sham-ECS treatment and subsequent training. They were housed six per double-wide cage $(28 \times 42 \mathrm{~cm})$ and were maintained on an ad-lib food and water schedule throughout the experiment. The rats were maintained on a light-dark cycle, with the light onset at 1:00 p.m. and offset at 1:00 a.m. local time for 6 weeks prior to the beginning of the experiment.

Table 1

Treatment Variables, Predicted Effects on Brain ACh Excitability and Performance, and Obtained Mean Trials to Criterion

\begin{tabular}{|c|c|c|c|c|c|c|}
\hline $\begin{array}{c}\text { ECS } \\
\text { Condition }\end{array}$ & $\begin{array}{l}\text { Training Time After } \\
\text { ECS or SECS }\end{array}$ & $\begin{array}{c}\text { Light-Dark } \\
\text { Cycle }\end{array}$ & Drug & $\begin{array}{c}\text { Predicted ACh } \\
\text { Excitability }\end{array}$ & $\begin{array}{l}\text { Predicted Per- } \\
\text { formances* }\end{array}$ & $\begin{array}{r}\text { Trials to } \\
\text { Criterion } \\
\end{array}$ \\
\hline \multirow{4}{*}{ ECS } & \multirow{2}{*}{$4 \mathrm{~h}$} & Dark & $\begin{array}{l}\text { Physostigmine } \\
\text { Saline } \\
\text { Scopolamine }\end{array}$ & $\begin{array}{l}+3 \\
+2 \\
+1\end{array}$ & $\begin{array}{l}3 \\
2 \\
1\end{array}$ & $\begin{array}{l}48 \\
52 \\
25\end{array}$ \\
\hline & & Light & $\begin{array}{l}\text { Physostigmine } \\
\text { Saline } \\
\text { Scopolamine }\end{array}$ & $\begin{array}{r}+2 \\
+1 \\
0\end{array}$ & $\begin{array}{l}2 \\
1 \\
1\end{array}$ & $\begin{array}{l}57 \\
31 \\
30\end{array}$ \\
\hline & \multirow{2}{*}{$48 \mathrm{~h}$} & Dark & $\begin{array}{l}\text { Physostigmine } \\
\text { Saline } \\
\text { Scopolamine }\end{array}$ & $\begin{array}{r}+1 \\
0 \\
-1\end{array}$ & $\begin{array}{l}1 \\
1 \\
2\end{array}$ & $\begin{array}{l}18 \\
27 \\
70\end{array}$ \\
\hline & & Light & $\begin{array}{l}\text { Physostigmine } \\
\text { Saline } \\
\text { Scopolamine }\end{array}$ & $\begin{array}{r}0 \\
-1 \\
-2\end{array}$ & $\begin{array}{l}1 \\
2 \\
3\end{array}$ & $\begin{array}{l}33 \\
47 \\
93\end{array}$ \\
\hline \multirow{4}{*}{ Sham ECS } & \multirow{2}{*}{$4 \mathrm{~h}$} & Dark & $\begin{array}{l}\text { Physostigmine } \\
\text { Saline } \\
\text { Scopolamine }\end{array}$ & $\begin{array}{r}+2 \\
+1 \\
0\end{array}$ & $\begin{array}{l}2 \\
1 \\
1\end{array}$ & $\begin{array}{l}54 \\
21 \\
42\end{array}$ \\
\hline & & Light & $\begin{array}{l}\text { Physostigmine } \\
\text { Saline } \\
\text { Scopolamine }\end{array}$ & $\begin{array}{r}+1 \\
0 \\
-1\end{array}$ & $\begin{array}{l}1 \\
1 \\
2\end{array}$ & $\begin{array}{l}21 \\
57 \\
60\end{array}$ \\
\hline & \multirow{2}{*}{$48 \mathrm{~h}$} & Dark & $\begin{array}{l}\text { Physostigmine } \\
\text { Saline } \\
\text { Scopolamine }\end{array}$ & $\begin{array}{r}+2 \\
+1 \\
0\end{array}$ & $\begin{array}{l}2 \\
1 \\
1\end{array}$ & $\begin{array}{l}59 \\
19 \\
36\end{array}$ \\
\hline & & Light & $\begin{array}{l}\text { Physostigmine } \\
\text { Saline } \\
\text { Scopolamine }\end{array}$ & $\begin{array}{r}+1 \\
0 \\
-1\end{array}$ & $\begin{array}{l}1 \\
1 \\
2\end{array}$ & $\begin{array}{l}30 \\
31 \\
60\end{array}$ \\
\hline
\end{tabular}

\footnotetext{
${ }^{*} 1$ = best performances; 2 = intermediate performances; 3 = poorest performances.
} 


\begin{abstract}
Apparatus
A constant-current ECS device, similar to one described by Hayes (1948) and built by the University of Georgia Electronics Design and Maintenance Shop, was used. A 35-mA ECS of .5-sec duration was delivered via bilaterally placed ear clips. SECS animals were treated exactly as the ECS animals, except that the ECS was not actually delivered. Acquisition trials were given in the two-compartment avoidance apparatus described by Adams and Lewis (1962). Grason-Stadler electric shock and programming equipment was used to control the CS and UCS variables in training.
\end{abstract}

\section{Procedure}

The rats were assigned randomly to two groups to be trained following the administration of either ECS or sham ECS. These groups were further divided into groups to be trained 4 or $48 \mathrm{~h}$ following ECS or sham ECS. Each of these groups was divided into subgroups to be trained during either the light or the dark phase of the established light-dark cycle. Finally, these groups were divided into three subgroups (six rats per group) that received equal-volume intraperitoneal injections of saline ( $1 \mathrm{cc} / \mathrm{kg}$ body weight), scopolamine $(1 \mathrm{mg} / \mathrm{kg}$ body weight), or physostigmine $(.3 \mathrm{mg} / \mathrm{kg}$ body weight) $30 \mathrm{~min}$ prior to training trials. These doses were selected on the bases of their previous use in this laboratory (e.g., Davis, 1972; Davis et al., 1971) as well as their frequent use by investigators of "memory formation" (see extensive review by Gibbs \& Mark, 1973). Thus, the experimental design involved 24 groups (ECS vs. sham ECS by $4 \mathrm{~h}$ vs. $48 \mathrm{~h}$ by light vs. dark by physostigmine vs. saline vs. scopolamine), with six subjects per group.

The rats were placed into the black side of the avoidance box and were allowed $5 \mathrm{sec}$ after the door between the compartments was opened to move to the white side of the box. If the rat did not respond within the time limit, a $2-\mathrm{mA}(60 \mathrm{~Hz})$ footshock was delivered through the grid floor and was continued until the rat moved to the white side of the box. The intertrial intervals were approximately $10-15 \mathrm{sec}$. The training criterion was successful avoidance of the footshock by the animal of 9 of 10 successive trials. Training to criterion was completed in one experimental session.

\section{RESULTS AND DISCUSSION}

The predictions regarding postulated cholinergic excitability and acquisition of one-way avoidance were confirmed. Specifically, the combination of independent variables expected to result in the highest and lowest values representing cholinergic excitability were associated with the mean most trials to criterion (71), expected medial values representing excitability were associated with the mean fewest trials to criterion (30), and expected intermediate values of excitability were associated with mean trials to criterion (58) between those associated with the other sets of values.

Statistically, these results were supported by a rank-differences coefficient of correlations (corrected for ties; Siegel, 1956) of .79 $(p<.01)$ between the three categories (highest/lowest, medial, and intermediate) of postulated cholinergic excitability and mean trials to criterion. The data used to compute this coefficient may be seen in the last two columns of Table 1. Some of the variance not accounted for by this correlation coefficient is suggested in Figure 1 . As may be seen, when mean performances for all six predicted levels of cholinergic excitability are plotted

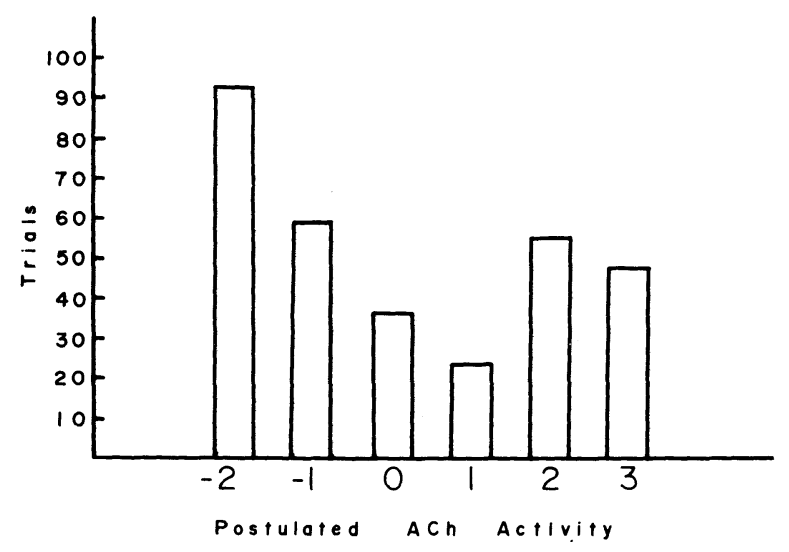

Figure 1. Mean trials to criterion as a function of postulated ACh activity (see last two paragraphs of introduction).

separately against trials to criterion, the +3 group performed better than anticipated. Owing to the consistency of the mean performances of the +2 groups (see Table 1 where the +2 groups had means of 52 , 57,54 , and 59 trials to criterion), it is suggested that the data from the single +3 group may be unreliable. Following analysis of variance (see next paragraph), Newman-Keuls analyses showed the following with respect to differences indicated in Figure 1 (all ps $<.01$ ). (1) Mean trials to criterion associated with the predicted $\mathrm{ACh}$ excitability values 0 to +1 were significantly different from all other values. (2) The mean for the -2 group differs significantly from all other values. No other differences were significant.

A four-way analysis of variance (ECS vs. SECS by 4 vs. $48 \mathrm{~h}$ by light vs. dark by saline vs. physostigmine vs. scopolamine) revealed a significant fourway interaction $[\mathrm{F}(2,120)=4.88, \mathrm{p}<.01]$. There were significant three-way interactions among the hours, drugs, and $E C S$ variables $[F(2,120)=33.03, p<.001]$, among the light-dark, drugs, and ECS variables $[\mathrm{F}(2,120)=19.18, \mathrm{p}<.001]$, and among the hours, light-dark, and ECS variables $[F(1,120)=7.90$, $\mathrm{p}<.01]$. There were significant two-way interactions between the ECS and hours variables $[F(1,120)=$ $5.44, p<.025]$ and between the hours and drugs variables $[F(2,120)=7.96, p<.01]$. Finally, among the main effects, differences related to the drugs $[F(2,120)=17.00, p<.001]$ and to the light-dark conditions $[F(1,120)=7.96, p<.01]$ were significant.

In view of the (1) significant interactions among the variables together with (2) the relatively strong correlation between obtained and predicted performances, the latter based on postulated cholinergic excitability as a function of the independent variables, and (3) the data shown in Table 1 and Figures 1 and 2 , it is reasonable to suggest, generally, that the independent variables had the expected separate and inter- 

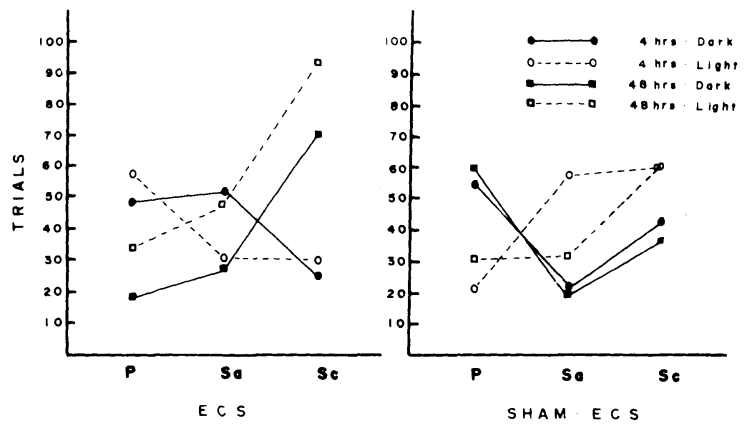

Figure 2. Mean trials to criterion as a function of the interactive effects of ECS or sham ECS administered 4 or $48 \mathrm{~h}$ prior to training, light-dark cycle, and physostigmine (P), Saline (Sa) or scopolamine (Sc) administrations.

active effects as indicated in the introduction. Two major departures from expectations were the ECS/4 hdark-physostigmine group, which performed better than expected, and the SECS/4 h-light-saline group, which performed more poorly than expected (see Figure 2).

In some respects, it was surprising that the results were as consistent with the predictions as they were. The assignment of numerical indices for the predicted cholinergic excitability reflects only ordinal measurement. Further research involving direct as well as indirect assessments of the effects of such variables as those manipulated here should increase the precision of measurement and, therefore, the accuracy of the predictions.

\section{DISCUSSION}

An issue which should be addressed is whether the differential effects of the treatments were due to effects on learning per se or some other aspect of performance. An experimental assessment of the learning-performance distinction in the present study, given the multiple variables and interactions considered here, would be impractical if not impossible to attain. It may be noted that there were no obvious differences among the subjects in their abilities to perform in the avoidance apparatus. It is appropriate to emphasize that the strong correlation between the predicted and obtained results seen here was based on postulated cholinergic excitability as a hypothetical construct which was used to relate the independent variables to the dependent variable. It is reasonable to ask whether one might predict corresponding general, nonlearned performance differences (e.g., locomotor or general activity) with cholinergic excitability as the mediating variable.

While physostigmine increases cholinergic excitbility, it decreases locomotor activity in rats (Hingtgen \& Aprison, 1976). While scopolamine, in the dosage used here, decreases cholinergic excitability, it in- creases locomotor activity (Hingtgen \& Aprison, 1976). While cholinergic excitability may be expected to be above normal $4 \mathrm{~h}$ post-ECS, general activity is below normal (Goble, 1967). With the two remaining AChinfluencing variables used here one might expect to see a correspondence between cholinergic excitability and general activity. Namely, training in the dark phase is associated with increased general activity (Peacock, Hodge, \& Thomas, 1966) and increased ACh release (Hanin et al., 1970), and training $48 \mathrm{~h}$ post-ECS is associated with below normal general activity (Goble, 1967) and, presumably, cholinergic excitability (Davis, 1972). All variables considered, then, one would not predict a strong or even significant correlation between cholinergic excitability as manipulated in the present work and general activity. To the extent that this reasoning applies to the present study, one might expect to see dissociation between cholinergic excitability and performance per se, on the one hand, and cholinergic excitability and learning per se, on the other.

The strong correlation between the predicted and obtained results seen here with postulated cholinergic excitability as the connecting variable in the predictions suggests strongly that $\mathrm{ACh}$ is important in the learning/memory process. However, it would be premature to preclude the possibility of significant relationships among the treatment variables here, the learning/ memory process, and other neural, hormonal and metabolic factors. For example, light-dark cycle is known to affect other neurotransmitters in addition to ACh (e.g., Scheving, Harrison, Gordon, \& Pauly, 1968), and Essman (1972), who was cited earlier to show that there are changes in brain ACh release following ECS, has emphasized the role of serotonin rather than $\mathrm{ACh}$ in the learning/memory process (1970). Nevertheless, it remains to be shown whether these, other neuroregulators (Barchas, Akil, Elliot, Holman, \& Watson, 1978) or other organismic factors may serve as successfully as ACh has here in the mediating role between the independent and dependent variables. Finally, of course, direct assessment of $\mathrm{ACh}$ following treatments such as those used in the present work will be necessary before a causal relationship between cholinergic excitability and the learning/ memory process may be asserted confidently.

\section{REFERENCES}

Adams, H. E., Hoblit, P. R., \& Sutke R, P. B. Electroconvulsive shock, brain acetylcholinesterase activity and memory. Physiology \& Behavior, 1969, 4, 113-116.

Adams, H. E., \& LEwis, D. J. Electroconvulsive shock, retrograde amnesia, and competing responses. Journal of Comparative and Physiological Psychology, 1962, 55, 299-301.

Barchas, J. D., Akil, H., Elliot, G. R., Holman, R. B., \& WAtson, S. J. Behavioral neurochemistry: Neuroregulators and behavioral states. Science, 1978, 200, 964-973.

DAvis, J. W. Acquisition of one-way avoidance in rats as cor- 
related with experimental alterations of brain acetylcholine activity. (Doctoral dissertation, University of Georgia, 1972.) Dissertation Abstracts International, 1972, 33, 3299-B. (University Microfilms No. 72-34, 062.)

Davis, J. W., Thomas, R. K., JR., \& Adams, H. E. Interactions of scopolamine and physostigmine with ECS and one trial learning. Physiology \& Behavior, 1971, 6, 219-222.

DEUTSCH, J. A. The cholinergic synapse and the site of memory. Science, 1971, 174, 788-794.

Deutsch, J. A., \& Rogers, J. B. Cholinergic excitability and memory: Animal studies and their clinical implications. In K. L. Davis \& P. A. Berger (Eds.), Brain acetylcholine and neuropsychiatric disease. New York: Plenum, 1979.

Essman, W. B. Some neurochemical correlates of altered memory consolidation. New York Academy of Sciences Transactions, 1970, 32, 948-973.

Essman, W. B. Neurochemical changes in ECS and ECT. Seminars in Psychiatry, 1972, 4, 67-79.

GiBBS, M. E., \& MARK, R. F. Inhibition of memory formation. New York: Plenum, 1973.

GoвLE, L. G. The effect of a single electroconvulsive shock on general activity. Unpublished master's thesis, University of Georgia, 1967.

Hanin, I., Massarelli, R., \& Costa, E. Acetylcholine concentrations in rat brain: Diurnal oscillation. Science, 1970, 170, 341-342.

HAYES, K. J. Cognitive and emotion effects of electroconvulsive shock on rats. Journal of Comparative and Physiological Psychology, 1948, 41, 40-61.

Hingtgen, J. N., \& Aprison, M. H. Behavioral and environ- mental aspects of the cholinergic system. In A. M. Goldberg \& I. Hanin (Eds.), Biology of cholinergic function. New York: Raven Press, 1976.

Peacock, L. J., Hodge, M. H., \& Thomas, R. K. Ultrasonic measurement and automatic analysis of general activity in the rat. Journal of Comparative and Physiological Psychology, 1966, 62, 284-288.

Prewett, M. J., \& Thomas, R. K. Interactions of ECS and a light-dark cycle on one-way avoidance learning in rats. Physiological Psychology, 1976, 4, 118-120.

Richter, D., \& Crossland, J. Variation in acetylcholine content of the brain with physiological state. American Journal of Physiology, 1949, 159, 247-255.

SaIto, Y. The circadian rhythm of brain acetylcholine levels and motor activity in the rat. Life Sciences, 1971, 10, 735-744.

Scheving, L. E., Harrison, W. H., Gordon, P., \& Pauly, J. E. Daily fluctuation (circadian and ultradian) in biogenic amines of the rat brain. American Journal of Physiology, 1968, 214, 166-173.

SIEGEL, S. Nonparametric statistics for the behavioral sciences. New York: McGraw-Hill, 1956.

Stephens, G., McGaugh, J. L., \& Alpern, H. P. Periodicity and memory in mice. Psychonomic Science, 1967, 8, 201-202.

WIENER, N. I. Electroconvulsive, shock induced impairment and enhancement of a learned escape response. Physiology \& Behavior, 1970, 5, 971-974.

(Received for publication October 30, 1979; revision accepted December 20, 1979.) 